\title{
Histological underestimation of a 9-gauge stereotactic vacuum-assisted breast biopsy system compared with surgical excision at a tertiary hospital in South Africa
}

\begin{tabular}{|c|c|}
\hline \multicolumn{2}{|c|}{$\begin{array}{l}\text { Authors: } \\
\text { Michael Pieters }{ }^{1} \\
\text { Susan Otto }{ }^{1} \\
\text { Gina Joubert }{ }^{2}\end{array}$} \\
\hline \multicolumn{2}{|c|}{$\begin{array}{l}\text { Affiliations: } \\
\text { }{ }^{1} \text { Department of Clinical } \\
\text { Imaging Sciences, } \\
\text { University of the Free State, } \\
\text { South Africa }\end{array}$} \\
\hline \multicolumn{2}{|c|}{$\begin{array}{l}{ }^{2} \text { Department of Biostatistics, } \\
\text { University of the Free State, } \\
\text { South Africa }\end{array}$} \\
\hline \multicolumn{2}{|c|}{$\begin{array}{l}\text { Correspondence author: } \\
\text { Michael Pieters, } \\
\text { pieters.ms@gmail.com }\end{array}$} \\
\hline \multicolumn{2}{|c|}{$\begin{array}{l}\text { Dates: } \\
\text { Received: } 13 \text { April } 2015 \\
\text { Accepted: } 30 \text { Nov. } 2015 \\
\text { Published: } 09 \text { June } 2016\end{array}$} \\
\hline \multicolumn{2}{|c|}{$\begin{array}{l}\text { How to cite this article: } \\
\text { Pieters M, Otto S, \& } \\
\text { Joubert G. The histological } \\
\text { underestimation of a 9-gauge } \\
\text { stereotactic vacuum-assisted } \\
\text { breast biopsy system } \\
\text { compared with surgical } \\
\text { excision at a tertiary hospital } \\
\text { in South Africa. S Afr J Rad. } \\
\text { 2016;20(1); a818. http:// } \\
\text { dx.doi.org/10.4102/sajr. } \\
\text { v20i1.818 }\end{array}$} \\
\hline \multicolumn{2}{|c|}{$\begin{array}{l}\text { Copyright: } \\
\text { (C) 2016. The Authors. } \\
\text { Licensee: AOSIS. This work } \\
\text { is licensed under the } \\
\text { Creative Commons } \\
\text { Attribution License. }\end{array}$} \\
\hline \multicolumn{2}{|l|}{ Read online: } \\
\hline 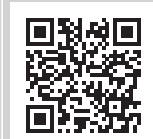 & $\begin{array}{l}\text { Scan this QR } \\
\text { code with your } \\
\text { smart phone or } \\
\text { mobile device } \\
\text { to read online. }\end{array}$ \\
\hline
\end{tabular}

Background: Breast cancer is a major cause of morbidity and mortality worldwide. Certain lesions encountered on mammography require histological assessment of biopsy samples to identify benign versus malignant disease. Stereotactic vacuum-assisted breast biopsy (SVAB) is a useful technique, especially for non-palpable microcalcific lesions, and was introduced at our institution in 2011.

Objectives: To determine whether the histological underestimation from 9-gauge SVABs performed at our institution is within acceptable limits.

Method: In this cross-sectional study, 9-gauge stereotactic biopsy histology results and breast imaging and reporting data system (BI-RADS) findings of 158 lesions (from 153 patients) were analysed and the histological findings compared with surgical excision histology results (54 lesions) to determine histological underestimation (upgrade rates).

Results: One out of eight cases of ductal carcinoma in situ (DCIS) was underestimated, yielding a DCIS underestimation rate of $12.5 \%$.

Conclusion: The DCIS underestimation obtained from the present study in our institution was on a par with other authors' findings and was therefore within acceptable limits. Atypical ductal hyperplasia underestimation could not be reliably obtained with the small study population.

\section{Introduction}

The most common malignancy in women globally is breast cancer. ${ }^{1}$ Screening mammography reduces breast cancer mortality, but numerous benign abnormalities that cannot be distinguished from malignancy ${ }^{2}$ are detected on mammography. Histological evaluation is therefore required for these abnormalities. ${ }^{2}$

Histologic underestimation occurs when a high-risk or malignant lesion which has been identified on percutaneous biopsy is incompletely characterised. ${ }^{3}$ Examples include ductal carcinoma in situ (DCIS) underestimation and atypical ductal hyperplasia (ADH) underestimation. DCIS underestimation occurs when a lesion characterised as DCIS yields infiltrating carcinoma on surgical biopsy. ADH underestimation occurs when a lesion characterised as ADH on percutaneous biopsy yields carcinoma on subsequent surgery. ${ }^{3}$ A small sample of a DCIS lesion may be interpreted as $\mathrm{ADH}$ by the pathologist. ${ }^{3}$ Histologic underestimation in lesions containing both $\mathrm{ADH}$ and DCIS as well as lesions containing both DCIS and infiltrating ductal carcinoma may be attributed to sampling error. ${ }^{3}$ The diagnosis of ADH or DCIS on percutaneous biopsy is an indication for subsequent therapeutic surgical excision because of the risk of carcinoma and invasive carcinoma residing within these lesions. ${ }^{3}$

An in-depth study by Parker et al. showed that percutaneous large-core breast biopsy is a reliable alternative to surgery. ${ }^{4}$ Non-operative accurate diagnosis of benign and malignant disease reduces the number of operations necessary for appropriate staging and management of breast cancer, and this is where stereotactic vacuum-assisted biopsy has a role to play.

Patient selection for neo-adjuvant therapy requires that prognostic information be available from non-operative diagnostic tumour samples. Assessment of histological grade on biopsy can aid in preoperative oncological planning and treatment decision-making, despite the limitations 
associated with the accuracy of grading core biopsies related to tumour sampling. ${ }^{6,7}$ It follows that the lower an institution's histological underestimation rate from stereotactic biopsies, the better the patient's pre-operative management will be.

Stereotactic vacuum-assisted breast biopsy (SVAB) yields larger volumes of tissue, allows sampling of lesions that are difficult to sample (microcalcifications, distortions), and allows several biopsies to be taken with a single pass. ${ }^{7}$ The vacuum-assisted biopsy device is powered by suction and utilises a rotational cutter to obtain several samples as the operator rotates the device through 360 degrees. The sample is suctioned into the specimen port for collection without removing the needle from the biopsy site. ${ }^{7}$ Compared with conventional core-needle biopsy, SVAB affords less targeting errors and lower underestimation and re-biopsy rates, as well as high patient acceptance, minimal post-procedural complications and good cost-effectiveness. ${ }^{7,8}$

Stereotactic localisation achieves accurate 3-dimensional lesion localisation (Figure 1) by utilising 15-degree spatially opposed mammographic images, which forms the basis of SVAB. ${ }^{9}$

Percutaneous core-needle biopsy has become the method of choice for the pathologic evaluation of clinically occult breast lesions. ${ }^{10}$ Vacuum-assisted biopsy is currently preferred to core-needle biopsy, especially for subclinical lesions and lesions displaying microcalcifications. ${ }^{11}$ SVAB was introduced in 1995 and allows better characterisation of breast lesions than conventional core-needle biopsy by employing larger gauge needles, thus yielding larger tissue specimens ${ }^{12,13}$ with a sensitivity and a predictive negative value of more than $99 \%{ }^{12}$

Utilisation of larger gauge needles yields more representative tissue samples (Figure 2), so decreasing the likelihood of false-negative or false-positive findings. ${ }^{9}$

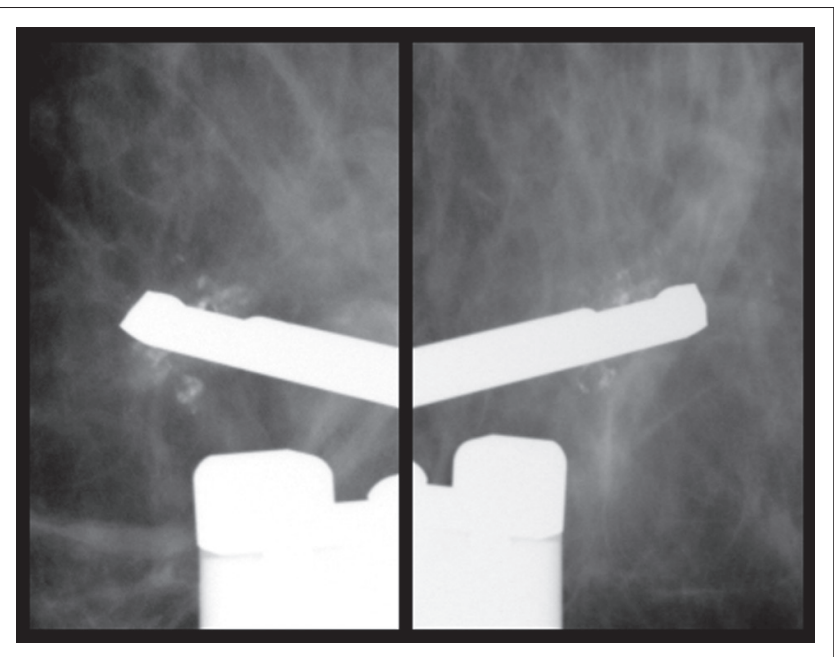

FIGURE 1: Post-fire 15-degree spatially opposed images taken during stereotactic vacuum-assisted breast biopsy. The tissue containing the pathological microcalcifications is suctioned into the open needle aperture before being automatically cut and suctioned into the specimen chamber. On pre-fire images, the needle should be slightly superficial and inferior to the lesion. On post-fire images (shown), the lesion should overlie the needle aperture.
SVAB has been offered by the Department of Clinical Imaging Sciences, Universitas Hospital, Bloemfontein, South Africa, since February 2011. SVAB is used for non-palpable lesions that are not visible on ultrasound in patients who have been screened by mammography at our institution.

The BI-RADS scoring system (breast imaging and reporting data system of the American College of Radiology) ${ }^{14}$ is used in our department, and SVAB is performed on all patients with mammographically demonstrated lesions where lesions are not visible on ultrasound with a BI-RADS score $\geq 4$. BI-RADS 3 lesions that are found in high-risk patients or that show progression on short-term follow-up are also stereotactically biopsied, provided that they are not demonstrable on ultrasound.

\section{Method}

The study was conducted at Universitas Academic Hospital, Bloemfontein, at the Faculty of Health Sciences of the University of the Free State. The study was a cross-sectional study including all patients (totalling 158 mammograms and stereotactic biopsies for 153 patients with a total of 158 lesions) who presented for opportunistic screening mammography and underwent SVAB at our institution from 01 February 2011 - 01 June 2014. All suspicious lesions that were visible on mammography, but not visible on ultrasound, were selected for SVAB as per BI-RADS guidelines and included in the study population. Asymmetric densities and distortions were included in the biopsy criteria, but none was encountered as the sole finding, and consequently all lesions biopsied included microcalcifications. Radiographic markers were left in situ after specimen retrieval to aid surgical localisation. All patients with ADH, DCIS or invasive ductal

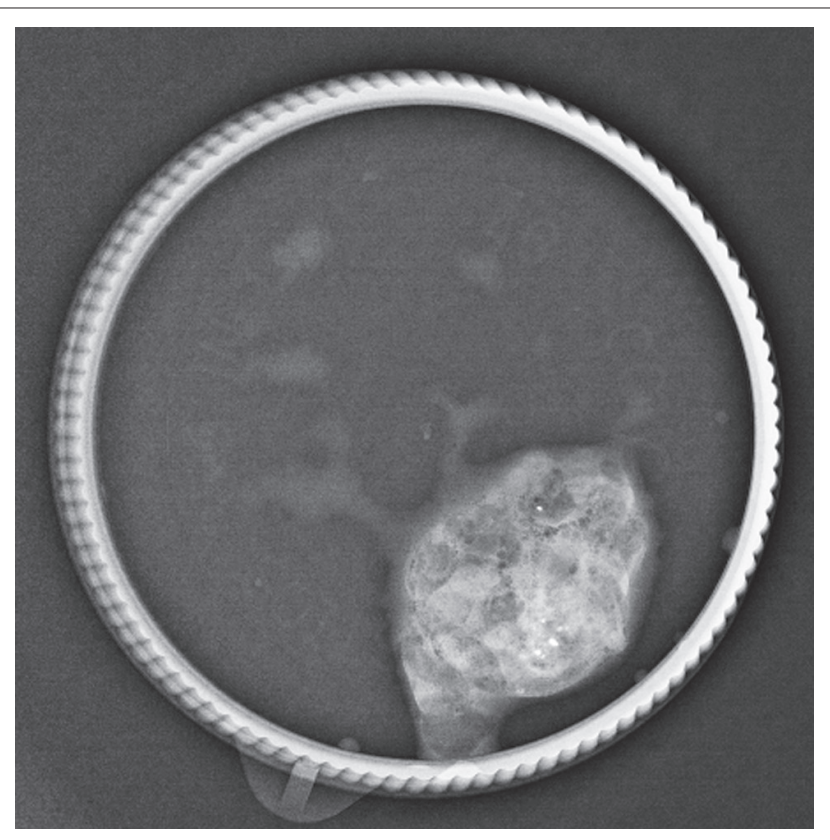

FIGURE 2: Stereotactic vacuum-assisted breast biopsy specimen view for documentation purposes and confirmation of intra-lesional microcalcifications. The use of a large-gauge needle (9-gauge) yields more representative tissue samples. 
carcinoma (IDC) on SVAB are routinely booked for surgical excision at our institution. Five patients were encountered twice in the data set for biopsies of the contra-lateral breast or separate lesions. Data for separate or contra-lateral lesions were incorporated into the dataset.

All patients in the study were imaged with a Selena Dimensions (Hologic, Massachusetts, USA) unit for mammography, and stereotactic biopsies were performed on a Multicare Platinum prone table unit (Hologic, Massachusetts) with a 9-gauge ATEC breast biopsy and excision system (Hologic, Massachusetts) (Figure 3).

All the biopsies were performed by our institution's breast imaging specialist radiologist. The histopathological data required for the study were retrieved from the Universitas Hospital's National Health Laboratory Service digital laboratory results system. Our departmental digital radiology picture archiving and communications system (PACS) records were utilised for BI-RADS and other information.

Histological findings at SVAB and open biopsy were classified into three groups: (1) the malignant category which included IDC, tubular carcinoma, mucinous carcinoma and micropapillary carcinoma as well as intermediate- or highgrade DCIS; (2) intermediate category lesions comprising low-grade DCIS, ADH and flat epithelial atypia (FEA); and (3) benign category lesions that included fibrocystic change, fibroadenoma, papilloma and other (e.g. apocrine metaplasia, sclerosing adenosis, granulomatous inflammation, fat necrosis and fibromatosis).

DCIS underestimation was defined as all lesions that were upgraded from DCIS to IDC on open biopsy. ADH underestimation was defined as all lesions that were upgraded to carcinoma on open biopsy.

The statistical analysis of data was done by the Department of Biostatistics, Faculty of Health Sciences, University of the Free State, Bloemfontein. Results were summarised by frequencies and percentages with $95 \%$ confidence intervals (CIs) for underestimation rates.

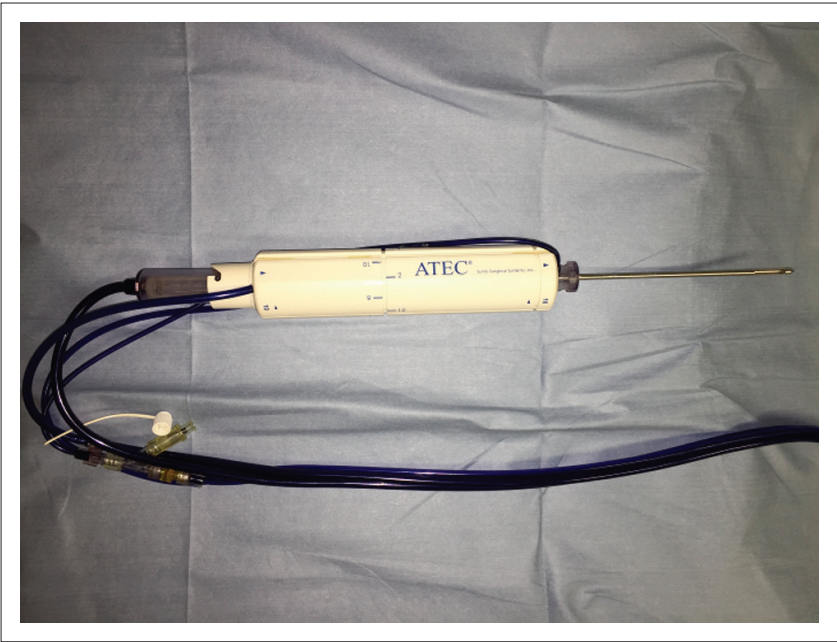

FIGURE 3: The Suros ATEC vacuum-assisted biopsy device.

\section{Results}

SVAB yielded 101 (63.9\%) benign category lesions, 7 (4.4\%) intermediate category (low-grade DCIS, ADH and FEA) and $45(28.5 \%)$ malignant category lesions (IDC and subtypes, intermediate- and high-grade DCIS), with 5 lesions $(3.2 \%)$ being non-representative (Table 1$)$. Of the IDC lesions, 2 were reported as exhibiting a mucinous growth pattern and 4 exhibiting a tubular growth pattern. One case of IDC was reported to display a micropapillary appearance, with the remainder reported as IDC alone. Of the 13 DCIS lesions, 4 lesions were low-grade DCIS, 2 lesions were intermediate-grade DCIS, and 7 lesions were high-grade DCIS on SVAB. Of 158 lesions that underwent SVAB, $54(34.2 \%)$ were followed on open biopsy. The average number of passes per biopsy was 6 . The mean age of the patients followed on open biopsy was 57 years (range $30-77$ years) and all were female. All of the 158 lesions that were excised by SVAB showed microcalcifications on their stereotactic biopsy specimen radiographs, thus yielding a calcification retrieval rate of $100 \%$.

Of the 54 lesions that were followed on open biopsy, 12 yielded benign findings (22.2\%), 8 yielded DCIS (14.8\%), and 34 yielded IDC (62.9\%). Of the 13 DCIS cases on SVAB, 5 were lost to follow-up. One case of DCIS was upgraded to IDC on open biopsy, yielding a DCIS underestimation rate of $12.5 \%(95 \% \mathrm{CI} 0.3 \%-52.7 \%)$.

Two cases (1.3\% of lesions) of ADH were found on SVAB in our study population, of which one was upgraded to IDC on subsequent open biopsy. A total of 5 (3.2\%) SVAB samples were deemed inadequate for evaluation. Of the 158 SVABs included in the study, $3(1.8 \%)$ cases had no BI-RADS information on record, leaving 155 patients with BI-RADS information. Seven cases (4.5\%) were representative of BI-RADS 3, $123(79.4 \%)$ of BI-RADS 4, and $25(16.1 \%)$ of BI-RADS 5. No BI-RADS 1 or BI-RADS 2 lesions were encountered in the records for SVAB.

\section{Ethical considerations}

Approval to conduct the study was obtained from the Ethics Committee of the Faculty of Health Sciences, University of the Free State (number ECOFS 24/2014). Patient confidentiality was maintained throughout.

\begin{tabular}{|c|c|c|}
\hline Histological finding & $n$ on SVAB & Total (\%) \\
\hline \multicolumn{3}{|l|}{ Malignant } \\
\hline IDC† & 36 & 22.8 \\
\hline DCIS high-grade & 7 & 4.4 \\
\hline DCISt intermediate-grade & 2 & 1.3 \\
\hline \multicolumn{3}{|l|}{ Intermediate } \\
\hline DCISt low-grade & 4 & 2.5 \\
\hline $\mathrm{ADH} \S$ & 2 & 1.3 \\
\hline FEA & 1 & 0.6 \\
\hline Benign & 101 & 63.9 \\
\hline Non-representative & 5 & 3.2 \\
\hline
\end{tabular}

$\dagger$, Infiltrating ductal carcinoma; $\$$, Ductal carcinoma in situ; $\S$, Atypical ductal carcinoma; ๆ, Flat epithelial atypia. 


\section{Discussion}

Internationally, false-negative rates for SVAB range from $1.3 \%-3.3 \%$, with underestimation rates from $11.8 \%-28.6 \%{ }^{7}$

Siegmann et al. found in their study population of 166 stereotactic biopsies using a mammotome system (Breast Care, Ethicon Endo-Surgery, Norderstedt, Germany) that the histology of a sufficient vacuum-assisted biopsy was underestimated in $15 \%$ of their study population when compared with histology at excision. ${ }^{15}$

Salem et al. reported an overall underestimation rate of $9.6 \%$ for high-risk lesions and a DCIS underestimation rate of $19.2 \%$ for a hand-held vacuum-assisted stereotactic biopsy device (Vacora vacuum-assisted biopsy system, Bard, Tempe, USA) in a study population of 288 stereotactic biopsies. ${ }^{12}$

Of the 13 cases of DCIS on SVAB in our study, 8 were followed with surgical excision, of which 1 case was upgraded to IDC on open biopsy, yielding a DCIS underestimation rate of $12.5 \%$. This figure compares favourably with the DCIS underestimation rate of $12 \%$ found in a study by Kettritz et al., ${ }^{2}$ of $23 \%$ in a study by Laurenco et al., ${ }^{5}$ and of $0 \%-19 \%$ quoted in the review article by Liberman. ${ }^{3}$

Two cases of ADH were found on SVAB in our study population, of which one was upgraded to IDC on subsequent open biopsy. A study by Khor ${ }^{16}$ (991 patients) in 2010 investigated the histological underestimation rate of $\mathrm{ADH}$ and showed an underestimation rate of $19.8 \%$. A larger study population would probably have yielded more cases of $\mathrm{ADH}$, with better clarification of $\mathrm{ADH}$ underestimation at our institution. Furthermore, the lack of an official screening programme (our institution offers opportunistic screening only) with the resultant lower volume of mammographic examinations might have contributed to the low ADH yield.

Of the total SVAB biopsy population with available BI-RADS information in our study, $79.4 \%$ were BI-RADS 4 lesions, $4.5 \%$ were BI-RADS 3 , and $16.1 \%$ were BI-RADS 5. No BI-RADS 1 or 2 lesions were biopsied stereotactically. Seven BI-RADS 3 lesions were found in high-risk patients, and these lesions were stereotactically biopsied. These figures are in keeping with current practice of obtaining histology through biopsy on all patients with BI-RADS scores of 4 and 5, and shortterm follow-up with possible biopsy for BI-RADS 3 lesions.

A factor that became evident from the present study is that many patients were not followed up with open biopsy. Of a total of 158 SVABs, 104 were not followed up with biopsy. The main reason for this is that most patients had benign lesions on SVAB that did not require open biopsy. Twentyone patients $(20.2 \%)$ with non-benign lesions were also not followed up with biopsy. Possible reasons for this include low socio-economic status, theatre backlogs, long-distance travel to the hospital, and the demise of patients. This finding needs to be further investigated.

\section{Limitations of the study}

The largest limiting factor was the small study population. As our institution started performing SVABs only in February 2011, the study population was not expected to be large, but most probably sufficient to gain a perspective on whether or not we were obtaining an acceptable histological yield.

A second possible limiting factor is the fact that a single operator performed all the SVABs, and hence the possible effect of a learning curve when initially using the stereotactic biopsy system.

\section{Conclusion}

The DCIS underestimation for our institution is on a par with other authors' findings and is therefore within acceptable limits. A revisitation of biopsy techniques and equipment is accordingly not deemed necessary to improve histological yield at our institution, although our findings warrant further investigation in order to gain a more accurate perspective, as $\mathrm{ADH}$ underestimation could not be reliably obtained with the small study population.

\section{Acknowledgments Competing interests}

The authors declare that they have no financial or personal relationships which may have inappropriately influenced them in writing this article.

\section{Authors' contributions}

M.P. (UFS) was the main author, responsible for the protocol, data collection and analysis, and compilation of the manuscript. G.J. (UFS) did the biostatistical analysis and proofreading. S.O. (UFS) was the study leader, and did the conceptualisation and proofreading.

\section{References}

1. World Health Organization. The global burden of disease 2004 update. Geneva: World Health Organization, 2004; p. 13.

2. Kettritz U, Rotter K, Schreer I, et al. Stereotactic vacuum-assisted breast biopsy in 2874 patients: A multicenter study. Cancer. 2004;100:245-251. http://dx.doi. org/10.1002/cncr.11887

3. Liberman L. Percutaneous imaging-guided core breast biopsy. Am J Roentgenol 2000;174:1191-1199. http://dx.doi.org/10.2214/ajr.174.5.1741191

4. Parker SH, Burbank F, Jackman RJ, et al. Percutaneous large-core breast biopsy: A multi-institutional study. Radiology. 1994;193:359-364 http://dx.doi.org/ A multi-institutional study. Radiolitiog.

5. Lourenco AP, Mainiero MB, Lazarus E, Giri D, Schepps B. Stereotactic breast biopsy: Comparison of histologic underestimation rates with 11- and 9-gauge
vacuum-assisted breast biopsy. Am J Roentgenol. 2007;189:275-279. http://dx. doi.org/10.2214/AJR.07.2165

6. Rakha EA, Reis-Filho JS, Baehner F, et al. Breast cancer prognostic classification in the molecular era : the role of histological grade. Breast Cancer Res. 2010;12:207 http://dx.doi.org/10.1186/bcr2607

7. O'Flynn EAM, Wilson ARM, Michell MJ. Image-guided breast biopsy: State-of-theart. Clin Radiol. 2010;65:259-70. http://dx.doi.org/10.1016/j.crad.2010.01.008

8. Lee KE, Kim HH, Shin HJ, Cha JH. Stereotactic biopsy of the breast using a decubitus table: Comparison of histologic underestimation rates between 11- and 8-gauge
vacuum-assisted breast biopsy. SpringerPlus. 2013;2:551. http://dx.doi.org/ 10.1186/2193-1801-2-551

9. Neal L, Tortorelli CL, Nassar A. Clinician's guide to imaging and pathologic findings in benign breast disease. Mayo Clin Proc. 2010;85:274-279. http://dx.doi. org/10.4065/mcp.2009.0656

10. Margenthaler JA, Duke D, Monsees BS, Barton PT, Clark C, Dietz JR. Correlation between core biopsy and excisional biopsy in breast high-risk lesions. Am J Surg. 2006;192:534-537. http://dx.doi.org/10.1016/j.amjsurg.2006.06.003 
11. Graesslin O, Antoine M, Chopier J, et al. Histology after lumpectomy in women with epithelial atypia on stereotactic vacuum-assisted breast biopsy. Eur J Surg Oncol. 2010;36:170-175. http://dx.doi.org/10.1016/j.ejso.2009.09.002

12. Salem C, Sakr R, Chopier J, Marsault C, Uzan S, Daraï E. Accuracy of stereotactic vacuum-assisted breast biopsy with a 10-gauge hand-held system. The Breast. 2009;18:178-182. http://dx.doi.org/10.1016/j.breast.2009.03.007

13. Bianchi S, Caini S, Renne G, et al. Positive predictive value for malignancy on surgical excision of breast lesions of uncertain malignant potential (B3) diagnosed by stereotactic vacuum-assisted needle core biopsy (VANCB): A large multi-institutiona study in Italy.
14. D’Orsi C, Sickles E, Mendelson E, Morris E. ACR BI-RADS atlas, breast imaging reporting and data system. Reston: American College of Radiology; 2013.

15. Siegmann KC, Wersebe A, Fischmann A, et al. Stereotactic vacuum-assisted breast biopsy - success, histologic accuracy, patient acceptance and optimizing the $\mathrm{BI}$ RADS-correlated indication. RoFo. 2003:175:99-104. http://dx.doi.org/10.1055/ $\mathrm{s}-2003-36600$

16. Kohr JR, Eby PR, Allison KH, et al. Risk of upgrade of atypical ductal hyperplasia after stereotactic breast biopsy: Effects of number of foci and complete removal of calcifications. Radiology. 2010;255:723-730. http://dx.doi.org/10.1148/radiol. 09091406 